\title{
Climate records in ancient Chinese diaries and their application in historical climate reconstruction - a case study of Yunshan Diary
}

\author{
Siying Chen ${ }^{1,2}$, Yun $\mathrm{Su}^{1,2}$, Xiuqi Fang ${ }^{1,2}$, and Jia $\mathrm{He}^{1,2}$ \\ ${ }^{1}$ Faculty of Geographical Science, Beijing Normal University, Beijing 100875, China \\ ${ }^{2}$ Key Laboratory of Environmental Change and Natural Disaster, Ministry of Education, \\ Beijing Normal University, Beijing 100875, China
}

Correspondence: Yun Su (suyun@bnu.edu.cn)

Received: 17 May 2020 - Discussion started: 20 May 2020

Revised: 27 July 2020 - Accepted: 14 August 2020 - Published: 6 October 2020

\begin{abstract}
Private diaries are important sources of historical data for research on climate change. Their advantages include a high veracity and reliability, accurate time and location information, a high temporal resolution, seasonal integrity, and rich content. In particular, these data are suitable for reconstructing short-term, high-resolution climate series and extreme climatic events. Through a case study of Yunshan Diary, authored by Bi Guo of the Yuan dynasty of China, this article demonstrates how to delve into climate information in diaries, including species distribution records, phenological records, daily weather descriptions and personal experiences of meteorological conditions. In addition, this article considers how to use these records, supplemented by other data, to reconstruct climate change and extreme climatic events on various timescales, from multidecadal to annual or daily. The study of Yunshan Diary finds that there was a relatively low amount of precipitation in central and southern Jiangsu Province in the summer of 1309; the winter of 1308-1309 was abnormally cold in the Taihu Lake basin. In the early 14th century at the latest, the climate in eastern China had begun to turn cold, which reflects the transition from the Medieval Warm Period to the Little Ice Age.
\end{abstract}

\section{Introduction}

Reconstruction of past climates can help better understand and respond to current climate change and predict future scenarios (PAGES, 2009). Historical documents are one of the primary sources of proxy data used to reconstruct past cli- matic information. Compared to natural proxy data (e.g. tree rings, ice cores and stalagmites), historical documents are advantageous in their spatial coverage, temporal resolution, dating accuracy, location accuracy and clarity of climatic significance (Zheng et al., 2014). Globally, most such historical documents are in China, Japan and Europe (Pfister et al., 2008). Thanks to its long history, China has enormous quantities of documentary data, including abundant climaterelated records which are uninterrupted for the past 2 millennia. This is China's exceptional advantage in historical climate research (Man, 2000).

There are four types of Chinese historical documents that contain climate information. These are (1) the traditional documents classified as jing (classics), shi (histories), zi (philosophies) and $j i$ (anthologies); (2) local gazettes compiled by magistrates; (3) archives of the Ming and Qing dynasties, represented by Qing $Y u L u$ (The Records of Sunny or Rainy Days) and Yu Xue Fen Cun (The Records on Rainfall Infiltration and Snowfall); and (4) private notes and diaries (Zhang, 1996; Ge et al., 2018). In China, diaries can be traced back 2 millennia to the Western Han dynasty. There are more than 1000 surviving ancient diaries (referring to diaries written before the collapse of the Qing dynasty in 1912) (Chen, 2004), of which approximately 200 contain weather or weather-related records (Ge et al., 2018). Currently, private diaries of the Ming and Qing dynasties, mostly authored by officials or men of letters, are used as one of the primary sources in historical climate research. However, compared to studies based on other documentary data (e.g. his- 
tory books, local gazettes and archives), historical climate studies based on data in diaries are relatively limited and mostly focused on the 17th to 20th century. Studies have been done mainly based on weather, phenological and personal perception records in diaries. The available results involve a number of areas, including the reconstruction of temperature series, extreme cold events, and the characteristics of temperature change (Chu, 1973; Fang et al., 2005; Liu and Man, 2012; Xiao et al., 2006; Zheng et al., 2015), the reconstruction of precipitation and the East Asian rainy season (also known as the Meiyu season) (Man et al., 2007; Xiao et al., 2008; Yan et al., 2011; X. Zhang et al., 2011, 2013a), dust weather (Fei et al., 2004, 2005, 2009; Zhang et al., 2006; Yang et al., 2013), and adaptive human behaviours (Zhang et al., 2007b). Researchers have also discussed the veracity and reliability of weather and climatic records in diaries (Zhang et al., 2007a, 2013a; Fei et al., 2009).

In Europe, weather diaries have been used to study temperature (Nordli, 2001), precipitation (Gimmi et al., 2007; Pfister et al., 1999), droughts (Linderholm and Molin, 2005) and climatic effects of volcanoes (Lee and Mackenzie, 2010) in historical periods, particularly the period from the 16th to the 19 th century. These diaries were mostly written by priests, farmers and scholars. For example, based on the weather records in the diary of an Italian priest, Raicich (2008) analysed temperature and precipitation conditions in Trieste in the period 1732-1749. Based on an English farmer's diary, Lee and Mackenzie (2010) identified climate abnormities in England in the 2 years following the eruption of Mount Tambora in 1815. In India, Adamson and Nash (2013, 2014) studied the onset date of the summer monsoon as well as monsoon precipitation based on private diaries and other documents. In Japan, diaries have been used to study summer temperatures (Mikami, 2008), the winter monsoon (Hirano and Mikami, 2008) and typhoon weather (Grossman and Zaiki, 2009). Diaries have also been used to investigate historical climate in other regions, including Australia (Gergis et al., 2012) and Africa (Grab and Nash, 2009; Nash and Grab, 2010).

Through a case study of a 14th-century diary, Yunshan Diary, this article illustrates the types and characteristics of historical climatic information recorded in ancient Chinese diaries and demonstrates how to use these records to analyse the characteristics of weather and climatic events as well as climate change on various timescales. Through the analysis of Yunshan Diary, the severe cold winter of 1308/09 in the Taihu Lake basin and the drought in the summer of 1309 in southern Jiangsu Province are identified. On a multidecadal scale, it is proved that the climate had begun to turn cold in the early 14 th century at the latest.

\section{Data sources}

\subsection{Brief introduction to Yunshan Diary}

The raw materials used in this study originated from Yunshan Diary, which is included in A Series of Diaries of the Jin and Yuan Dynasties published by Shanghai Bookstore Publishing House (Gu and Li, 2013). Yunshan Diary was written by Bi Guo (1280-1335), also called Tianxi Guo, a famous calligrapher and painter of the Yuan dynasty. Guo was born in present-day Zhenjiang in Jiangsu Province. He used to be a lecturer at local academies in Jiangsu and Jiangxi and a county official in Zhejiang (Yu, 1989). During the period recorded in Yunshan Diary, Guo resided in Zhenjiang, but he travelled multiple times on official business or to visit friends. The scope of travelling involves central and southern Jiangsu Province and northern Zhejiang Province, primarily within the Taihu Lake basin (TLB) (Fig. 1).

Situated in the Yangtze River Delta along the southeastern coast of China, the TLB $\left(119^{\circ} 3^{\prime}-121^{\circ} 54^{\prime} \mathrm{E}, 30^{\circ} 7^{\prime}-32^{\circ} 14^{\prime} \mathrm{N}\right)$ encompasses an area of $3.69 \times 10^{4} \mathrm{~km}^{2}$. Except for a few low mountains and hills in the western region, it is mostly dominated by flat plains (altitudes below $10 \mathrm{~m}$ ). With the highest drainage density in China, the TLB is home to numerous rivers and lakes, and the Taihu Lake is China's thirdlargest freshwater lake. The TLB has a subtropical monsoon climate. North winds prevail in the cold and dry winter, while southeast winds prevail in the hot and rainy summer. The annual average precipitation here is $1000-1400 \mathrm{~mm}$ (19511980; the same below); the annual average temperature is $15-16^{\circ} \mathrm{C}$, and the average temperature in January is $1.5-4{ }^{\circ} \mathrm{C}$ (Huang, 2000; Wu et al., 1993; Xu et al., 2017).

Covering a total of 16 months, from 12 September 1308 to 2 December 1309, Yunshan Diary contains daily records of Guo's work and life, together with daily weather descriptions on most days. In this study, the dates in the diary (originally on the lunar calendar) were converted to dates on the Gregorian calendar according to The Chinese Almanac for Two Thousand Years (Perpetual calendar editing group, 1994). For example, a record reads, "It is sunny on the second day of the ninth lunar month of the first year of Zhida (至大元年九月初二, 晴)", and the date can be converted to 16 September 1308. All the dates in this article are Gregorian dates. The ancient place names in the diary were converted to the corresponding present-day city or county names according to The Historical Atlas of China (Tan, 1982).

\subsection{Other data}

For quantification and comparison purposes, modern meteorological data from instrumental measurements were used in this study. These data originated primarily from the collections of early instrumental data (The reference room of Beijing meteorological centre, 1984) and the China Meteorological Data Service Center (http://data.cma.cn/, last access: 
(a)

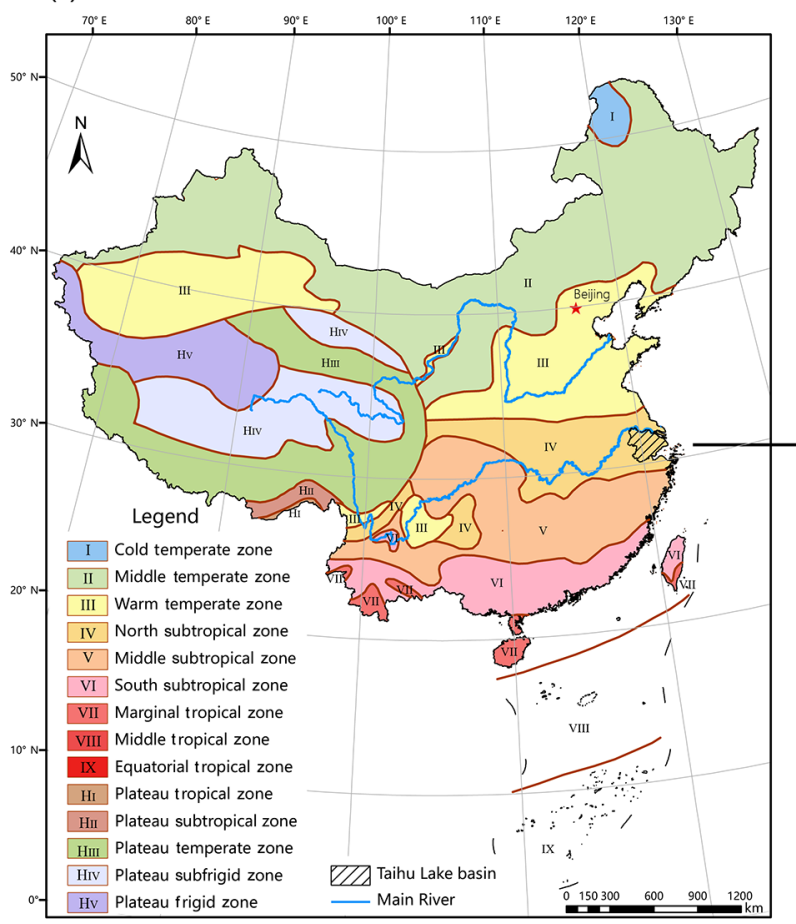

(b)

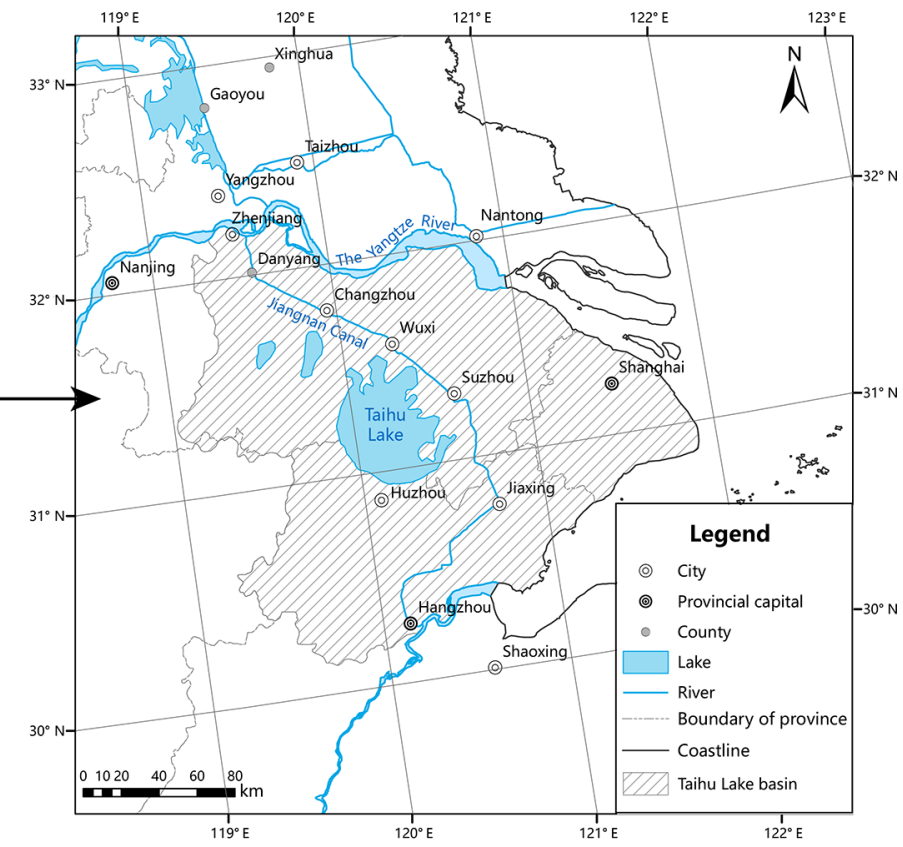

(c)

\begin{tabular}{cl|ll}
\hline \multicolumn{1}{c|}{ Time period } & \multicolumn{1}{c}{ Site } & \multicolumn{1}{c}{ Time period } & Site \\
\hline $1308 / 09 / 12-1308 / 09 / 30$ & Zhenjiang & $1309 / 04 / 30-1309 / 05 / 03$ & Changzhou \\
$1308 / 10 / 01-1308 / 10 / 06$ & Zhenjiang-Changzhou-Suzhou-Hangzhou & $1309 / 05 / 04-1309 / 05 / 05$ & Changzhou-Zhenjiang \\
$1308 / 10 / 07-1308 / 11 / 16$ & Hangzhou & $1309 / 05 / 06-1309 / 07 / 08$ & Zhenjiang \\
$1308 / 11 / 17-1308 / 11 / 19$ & Hangzhou-Huzhou & $1309 / 07 / 09-1309 / 07 / 11$ & Zhenjiang-Yangzhou-Gaoyou-Xinghua \\
$1308 / 11 / 20-1308 / 12 / 27$ & Huzhou & $1309 / 07 / 12-1309 / 07 / 31$ & Xinghua \\
$1308 / 12 / 28-1309 / 01 / 05$ & Huzhou-Suzhou-Wuxi-Zhenjiang & $1309 / 08 / 01-1309 / 08 / 04$ & Xinghua-Gaoyou-Yangzhou-Zhenjiang \\
$1309 / 01 / 06-1309 / 01 / 26$ & Zhenjiang & $1309 / 08 / 05-1309 / 10 / 11$ & Zhenjiang \\
$1309 / 01 / 27-1308 / 01 / 28$ & Zhenjiang-Changzhou & $1309 / 10 / 12-1309 / 10 / 13$ & Zhenjiang-Changzhou \\
$1308 / 01 / 29-1309 / 02 / 08$ & Changzhou & $1309 / 10 / 14-1309 / 10 / 17$ & Changzhou \\
$1309 / 02 / 09-1309 / 02 / 10$ & Changzhou-Zhenjiang & $1309 / 10 / 18-1309 / 10 / 19$ & Changzhou-Zhenjiang \\
$1309 / 02 / 11-1309 / 04 / 27$ & Zhenjiang & $1309 / 10 / 20-1309 / 12 / 02$ & Zhenjiang \\
$1309 / 04 / 28-1309 / 04 / 29$ & Zhenjiang-Changzhou & &
\end{tabular}

Figure 1. Map of the study area. (a) Climatic regionalization and location of the TLB (Wang and Zuo, 2010). (b) The scope of Guo's travelling. (c) Guo's travelling route.

14 March 2020). All the data were published by the National Meteorological Information Center of China Meteorological Administration.

Modern phenological data originated primarily from the collections of observation data of the Chinese Phenological Observation Network (Wan, 1986; Wan and Liu, 1986). Some phenological data about meteorological events were extracted from the Daily Surface Climate Dataset for China (V3.0).

\section{Extraction of historical climatic information and the reconstruction of weather and climate}

On the whole, climate records in historical documents can be classified into four categories based on the content (Zheng et al., 2014), (1) weather records, including qualitative descriptions (such as sunny, cloudy and rainy) and quantitative observation (such as the infiltration depth of each precipitation event in $Y u$ Xue Fen Cun); (2) meteorological disas- 
ter records, such as floods, droughts, and their impacts on agriculture and society; (3) phenological records, such as the flowering date of plants, the migration date of birds; and (4) records relating to the characteristics of regional climate, such as cropping system, distribution range of specific crops and fruits, the southern boundary of snowfall, and the southern boundary of river freezing. As one kind of private document, the diary contains records of personal experiences of meteorological conditions additionally, which record authors' subjective feelings about the weather (such as warm and cold). All the records relating to weather and climate in Yunshan Diary were excerpted based on a comprehensive read. In addition, the time and location of each weather or climatic event were recorded.

Four types of information were extracted from Yunshan Diary, namely, species distribution records (one), phenological records (six), daily weather descriptions (342), and personal experiences of meteorological conditions (87).

\subsection{Species distribution records and their climatic significance}

\subsubsection{Species distribution records}

The distribution range of plant and animal species is adapted to the zonal climatic characteristics of the region and reflects the average climatic conditions over decades (Zheng et al., 2014). The species distribution range is limited by environmental conditions (Gong et al., 1983a). If there is a definite and predominant climate-limiting factor for the survival of a certain species, its distribution range may be an indicator of the climate (Man, 2009). For example, the planting areas of zonal crops and fruit trees may indicate the climatic characteristics of the region on a multidecadal scale. Phased climate change and the movement of the climatic zone can be deduced by comparing the planting areas between time periods (Zheng et al., 2014).

The study area is located in the lower reaches of the Yangtze River and belongs to the north subtropical zone. Central and southern areas of Jiangsu Province are close to the northern boundary of the north subtropical zone, one of the regions that is most sensitive to climate change in China (Zhang, 1996). Within this region, the main species with notable climatic significance are subtropical crops, animals and plants. (1) The northern planting boundary of doublecropping rice roughly corresponds to $\geq 10^{\circ} \mathrm{C}$ active accumulated temperature of $4800^{\circ} \mathrm{C}$ (Zheng et al., 2014). The lower reaches of the Yangtze River are close to the northern planting boundary of double-cropping rice. Since the Tang dynasty, the rise and fall of double-cropping rice in the study area has approximately corresponded to climate change in terms of temperature (Man, 2009; Zhang, 1996). (2) For subtropical plants, such as citrus and tea trees, their growing areas are primarily limited by winter temperatures and freezing injury. The northern planting boundary of these plants is close to the northern boundary of the subtropical zone (Man, 1999; Man and Yang, 2014; Zhang et al., 2019). (3) For subtropical animals, such as rhizomys, elephants, buffalos and Chinese alligators, their distribution ranges are affected by human activities to a large extent. As a result, the distribution range of animals is less accurate than that of plants as climate indicators (Gong et al., 1983a).

One species distribution record was excerpted from Yunshan Diary, which was recorded during Guo's sojourn in Hangzhou in 1308. It reads, "there are several dwarf citrus trees outside the window, bearing countless fruits, which weighed down and almost broke the branches; there are no such trees in my hometown".

\subsubsection{Climatic significance of the species distribution record}

Citrus is a typical kind of subtropical perennial fruit, which prefers a warm, humid climate. It is sensitive to low temperatures and can be easily hit by freezing injury. The winter minimum temperature is the primary factor that limits the northern planting boundary of citrus (Man, 1999), which cannot go past the isoline of a multiyear average extreme minimum temperature lower than $-9{ }^{\circ} \mathrm{C}$ (Zheng et al., 2014). Citrus is native to China. China has a history of nearly 3 millennia of citrus tree cultivation. Thus, there are rich, comparable records for citrus planting locations in the historical documents. Therefore, in China, the northern planting boundary and southern freeze-to-death boundary of citrus are widely used indices in the study of climate change on a long timescale (Chu, 1973; Gong and Zhang, 1983; Man, 1998; Zhang et al., 1977; Zhang, 1996).

Man systematically collated the changes in the northern planting boundary of citrus between the Spring and Autumn Period and the Qing dynasty and discussed their correlation with climate change (Man, 1999). In the mid-13th century, the citrus planting area reached at least Nanyang $\left(33.0^{\circ} \mathrm{N}\right)$ in Henan and Nanjing $\left(32.2^{\circ} \mathrm{N}\right)$ in Jiangsu. Orange trees, which are relatively cold resistant, were once planted in Jiaozuo $\left(35.2^{\circ} \mathrm{N}\right)$ in northwestern Henan. In the mid-Ming dynasty, citrus planting records only appeared in Shanghai $\left(31.3^{\circ} \mathrm{N}\right)$ and Taicang $\left(31.5^{\circ} \mathrm{N}\right)$ in the Yangtze River Delta. Further north, there were only records of orange plantings in Dantu $\left(32.1^{\circ} \mathrm{N}\right)$, Tongzhou $\left(32.0^{\circ} \mathrm{N}\right)$ and Rugao $\left(32.3^{\circ} \mathrm{N}\right)$. In the early Qing dynasty, no citrus planting records are available in Shanghai.

According to the records in Yunshan Diary, in the early 14th century, citrus was planted in Hangzhou $\left(30.2^{\circ} \mathrm{N}\right)$, whereas no citrus was planted in Zhenjiang $\left(32.2^{\circ} \mathrm{N}\right)$, Guo's hometown. The latitude of Zhenjiang is similar to that of Nanjing. Evidently, the northern planting boundary of citrus was further south in this period than in the mid-13th century. This suggests that the climate had begun turning from warm to cold. 


\subsection{Phenological records and their climatic significance}

\subsubsection{Phenological records}

Phenology is the study of the times of recurring natural phenomena especially in relation to climate and weather (Vliet and De Groot, 2003). Here, the broad definition is adopted - that is, phenological phenomena include not only recurrent biological phenomena but also recurrent meteorological or hydrological phenomena, such as the timing of frost, snow and river freezing. There are three main types of phenological phenomena, namely, phenological phenomena of plants (including the sprouting, leafing, flowering, and defoliation of woody plants and the sowing, farming, and harvesting of crops), phenological phenomena of animals (including the arrival, first warble, last warble, departure, and hibernation of migratory birds, insects, and other animals), and the periodicity of meteorological or hydrological events (including the first frost, last frost, first snow, last snow, and freezes and thaws of rivers and lakes).

Advances or delays in phenological phases are primarily affected by climatic factors, particularly temperature. The basic approach for reconstructing historical climate change based on phenology is as follows. The phenological dates in historical records are compared with those of the same phenological phenomena at the same location in modern times, and the differences of the climate factors between the ancient and present times are deduced from the relationship between phenology and climate (Liu et al., 2017). Three factors, namely, time, location and phenological event, need to be clarified when constructing historical climate based on phenological records. Compared to records from other data sources (e.g. agricultural books and poems), it is relatively easy to verify the time and location of records in private diaries, but the phenological events require careful textual research.

In this study, potential phenology-related records were identified in Yunshan Diary and further examined to determine their veracity. For example, on 6 October 1308, Guo was in Hangzhou and wrote the following in Yunshan Diary: "There was a frosted moon all over the sky and chilly air". While he mentioned "frosted" and "chilly", this record is insufficient to suggest that the first frost in Hangzhou in 1308 occurred on 6 October. First, “frosted moon (霜月)" is a fixed phrase in Chinese, which appears more than 40 times in Complete Tang Poems alone. Frosted moon refers to a cold night's moon. In this term, the moon is likened to frost to highlight its pure white colour and coldness (Chen, 2018). For example, in one of his poems, Zhenbai Wang of the Tang dynasty wrote, "a frosted moon is setting". Second, no frostrelated records appear again in the diary over the period of more than a month between 6 October, when Guo wrote, "a frosted moon all over the sky" in his diary, and 11 November, when Guo left Hangzhou. Instead, there are some records relating to hot weather in the diary. For example, Guo wrote,
"The inn was very warm, and my clothes were drenched in sweat, so I kept shaking a fan", on 10 October and "It rained again, humid and hot", on 25 October in his diary. Therefore, the frosted moon in the abovementioned record is a literary expression and should not be used as evidence for the phenological event of first frost.

A total of six phenological records were identified from Yunshan Diary (Table 1).

The species corresponding to the phenological records of animals and plants in Yunshan Diary were identified, and their present-day names were determined. In addition, the phenological phases were defined according to the text description in the diary on the basis of modern phenological observation methods. Here, the fifth phenological record in Table 1 is used as an example. In Yunshan Diary, there is a record of the blooming of peach and plum flowers in Zhenjiang on 29 March 1309. The relevant record reads, "At dusk, I went out of the gate of the Ganlu Temple. I looked outside of the Dingbo Gate, seeing peach and plum flowers, red and white." In China, Prunus davidiana Franch is distributed primarily in the middle and lower reaches of the Yellow River, whereas Prunus persica (L.) Batsch is distributed primarily in the Yangtze River basin and Huaihe River basin (Gong et al., 1983a). The modern full flowering stage of Prunus persica (L.) Batsch occurs between 14 March and 15 April in Zhenjiang (Wan, 1986). Based on the geographical distribution and phenological phase, it can be deduced that the "peach" in the diary refers to Prunus persica (L.) Batsch. The modern unified observed flowering stage of woody plants is divided into three substages, the first flowering stage, the full flowering stage and the end of flowering stage. The full flowering stage for woody plants is defined as "the stage when petals have unfolded from more than half of the flower buds on the observed trees" (Wan and Liu, 1979). According to the record in Yunshan Diary, Guo stood by the gate of the Ganlu Temple and looked outside of the Dingbo Gate. The Ganlu Temple is approximately $1 \mathrm{~km}$ away from the historic site of the Dingbo Gate. The fact that Guo could see a scene of "peach and plum flowers, red and white" from such a distance suggests that the flowers must have been in high bloom and met the aforementioned requirement - "petals have unfolded from more than half of the flower buds". Therefore, it can be deduced that Prunus persica (L.) Batsch was in the full flowering stage on 29 March of that year.

\subsubsection{Climatic significance of the phenological records}

Of the six phenological records in Yunshan Diary, one was from the fall of 1308, two were from the winter of 1308, two were from the spring of 1309, and one was from the summer of 1309. Corresponding phenological phases in modern times at the same locations can be found for three of the records. A comparison can help deduce the climatic conditions at that time. 
Table 1. Phenological records in Yunshan Diary.

\begin{tabular}{|c|c|c|c|}
\hline Gregorian date & Location & Phenological phenomenon & Textual descriptions \\
\hline 29 November 1308 & Huzhou & Rice harvesting & $\begin{array}{l}\text { I heard my neighbours threshing rice grains. The children sang } \\
\text { the songs of Wu without stopping throughout the night, } \\
\text { which I did not hear in my hometown. It was a scene } \\
\text { of a bumper harvest year. }\end{array}$ \\
\hline 14 December 1308 & Huzhou & First snow & $\begin{array}{l}\text { It was raining and graupelling, so I could not go out. } \\
\ldots \text { After drinking, graupel fell heavily again. }\end{array}$ \\
\hline 21 December 1308 & Huzhou & First freezing & There was frost. The water was frozen. \\
\hline 9 March 1309 & Zhenjiang & Last snow & Snow fell heavily after the light was lit. \\
\hline 29 March 1309 & Zhenjiang & $\begin{array}{l}\text { Full flowering of peach } \\
\text { and plum flowers }\end{array}$ & $\begin{array}{l}\text { I looked outside of the Dingbo Gate, seeing peach } \\
\text { and plum flowers, red and white. }\end{array}$ \\
\hline 10 July 1309 & Yangzhou-Gaoyou & $\begin{array}{l}\text { Full flowering of } \\
\text { lotus flowers }\end{array}$ & $\begin{array}{l}\text { Today, I travelled on a boat. There were red and white } \\
\text { lotus flowers in the shallow water, never-ending } \\
\text { over tens of li. This was a marvellous spectacle. }\end{array}$ \\
\hline
\end{tabular}

The first snow in Huzhou in the winter of 1308 occurred on 14 December, $17 \mathrm{~d}$ earlier than the modern (1957-1979) average first-snow date of 31 December. According to the climate formation mechanism, an advance in the first-snow date in China is often related to the time of the southward movement of cold air masses from their source region, Siberia (Zheng et al., 2005). This suggests that the winter of 13081309 was relatively colder than usual, with stronger winter monsoon winds and a lower average temperature.

The last snow in Zhenjiang in the spring of 1309 occurred on 9 March, compared to the present-day average last-snow date of 7 March (Wan, 1986). The full flowering stage of Prunus persica (L.) Batsch in Zhenjiang in 1309 occurred on 29 March, compared to the present-day average full flowering date of 1 April (Wan, 1986; Wan and Liu, 1986). These two phenological phenomena can both reflect the temperature in spring. The last-snow date is primarily related to the time of reductions in the activity of cold air masses (Zheng et al., 2005). The time of the phenological phases of plants in spring is closely related to the temperature in the period before. The higher the temperature is, the more rapidly plants develop and the earlier the phenological phenomenon occurs (Gong et al., 1983b). There are no significant differences in the last-snow date and full flowering date of Prunus persica (L.) Batsch between the spring of 1309 and the present time. This suggests that the temperature in the spring of 1309 was close to the modern average spring temperature.

\subsection{Daily weather descriptions, personal experiences of meteorological conditions and their climatic significance}

\subsubsection{Daily weather descriptions}

In addition to recording his daily activities, Guo often briefly described the weather conditions of the day. Generally, weather conditions were recorded on a daily timescale and described using simple words, like cloudy, sunny, rainy and snowy. Changes in weather conditions within a day were sometimes recorded, and precipitation was also sometimes described in detail. Records of weather descriptions were excerpted on a daily timescale. They can be classified into three main types, namely, sunny, cloudy and precipitation (including rainy and snowy). Other weather descriptions, including windy, frost, fog and so on, were marked as "other". If there was no record of weather on a certain day, it is marked as "missing". When no direct weather descriptions are available, deductions can sometimes be made based on other text descriptions. For example, a sunny day can be deduced from a description of Guo's outdoor activities in the open air.

There are a total of 342 records of daily weather descriptions in Yunshan Diary, and the integrity rate is $67.8 \%$. Table 2 summarizes the monthly statistics of each weather type in Yunshan Diary.

\subsubsection{Personal experiences of meteorological conditions}

In addition to recording objective weather phenomena, Guo sometimes recorded his subjective feelings of the weather conditions. These records are scattered and appeared primarily on days with relatively extreme weather conditions or a sudden change in weather. A total of 87 records of personal experiences of meteorological conditions were extracted from Yunshan Diary. These records can be classified into three types, namely, perceptions of temperature changes (mainly represented by "cold", "hot", "warm" and "cool"), the effects of weather conditions on humans" lives (e.g. "clothes drenched in sweat" and "unable to sleep in the cold night") and humans' responses to weather changes (e.g. "it has been very cool for several days, so I put on clothes with lining"). It is difficult to quantify and compare these 
Table 2. Monthly statistics of the number of days for each weather type.

\begin{tabular}{llrrrr|r|r}
\hline Month & Main locations & Sunny & Precipitation & Cloudy & Other & Missing & Integrity rate \\
\hline September 1308* & Zhenjiang & 12 & 4 & 1 & 0 & 2 & $89.5 \%$ \\
October 1308 & Hangzhou & 8 & 16 & 3 & 1 & 3 & $90.3 \%$ \\
November 1308 & Hangzhou and Huzhou & 20 & 1 & 1 & 2 & 6 & $80.0 \%$ \\
December 1308 & Huzhou & 8 & 9 & 2 & 4 & 8 & $74.2 \%$ \\
January 1309 & Changzhou and Zhenjiang & 14 & 2 & 2 & 3 & 10 & $67.7 \%$ \\
February 1309 & Changzhou and Zhenjiang & 10 & 9 & 3 & 2 & 4 & $85.7 \%$ \\
March 1309* & Zhenjiang & 11 & 9 & 2 & 1 & 8 & $74.2 \%$ \\
April 1309 & Zhenjiang & 11 & 7 & 2 & 0 & 10 & $66.7 \%$ \\
May 1309 & Changzhou and Zhenjiang & 11 & 6 & 0 & 0 & 14 & $54.8 \%$ \\
June 1309* & Zhenjiang & 7 & 7 & 0 & 0 & 16 & $46.7 \%$ \\
July 1309 & Zhenjiang and Xinghua & 3 & 3 & 0 & 1 & 24 & $22.6 \%$ \\
August 1309 & Zhenjiang & 11 & 6 & 0 & 1 & 13 & $58.1 \%$ \\
September 1309* & Zhenjiang & 4 & 8 & 2 & 0 & 16 & $46.7 \%$ \\
October 1309 & Zhenjiang and Changzhou & 23 & 4 & 0 & 0 & 4 & $87.1 \%$ \\
November 1309* & Zhenjiang & 15 & 4 & 4 & 0 & 7 & $76.7 \%$ \\
December 1309 & Zhenjiang & 0 & 1 & 1 & 0 & 0 & $100.0 \%$ \\
\hline
\end{tabular}

Notes: main locations refers to the locations where Guo stayed more than $3 \mathrm{~d}$ within the month. The locations Guo passed by but did not stay at are not included. * indicates that Guo stayed at only one location for the entire month. Yunshan Diary covers the period from 12 September 1308 to 2 December 1309. Thus, records are available for only $19 \mathrm{~d}$ in September 1308 and $2 \mathrm{~d}$ in December 1309.

records. Thus, they are only used as qualitative indices to supplement weather descriptions.

\subsubsection{Characteristic analysis of monthly or seasonal precipitation based on daily weather descriptions}

By continuous tracing daily weather descriptions, it is possible to reconstruct a certain weather event or weather conditions in a certain month or season.

In eastern China, there is a positive correlation between monthly precipitation and monthly number of precipitation days. The number of precipitation days for each month can be determined through the statistics of daily weather descriptions, so it is possible to estimate the precipitation based on the correlation. In this way, the precipitation of each month in 1309 in Zhenjiang is reconstructed. However, in February, the author was out of Zhenjiang for more than a third of a month; in July, the author mainly stayed in Xinghua instead of Zhenjiang; in December, there were only $2 \mathrm{~d}$ of records. In order to reduce uncertainty, these 3 months were not included in the analysis. Let $P$ be monthly precipitation. It is worth noting that Guo frequently took excursions and rarely stayed an entire month in Zhenjiang and thus missed some precipitation events. For comparison purposes, assuming that precipitation days are evenly distributed within a month, the proportion of precipitation days $(R)$ is defined as follows. For the instrument-measurement period, $R$ is the number of precipitation days in Zhenjiang divided by the total number of days of the month. For $1309, R$ is the number of precipitation days in Zhenjiang recorded in Yunshan Diary divided by total number of days when Guo stayed in Zhenjiang in that month.

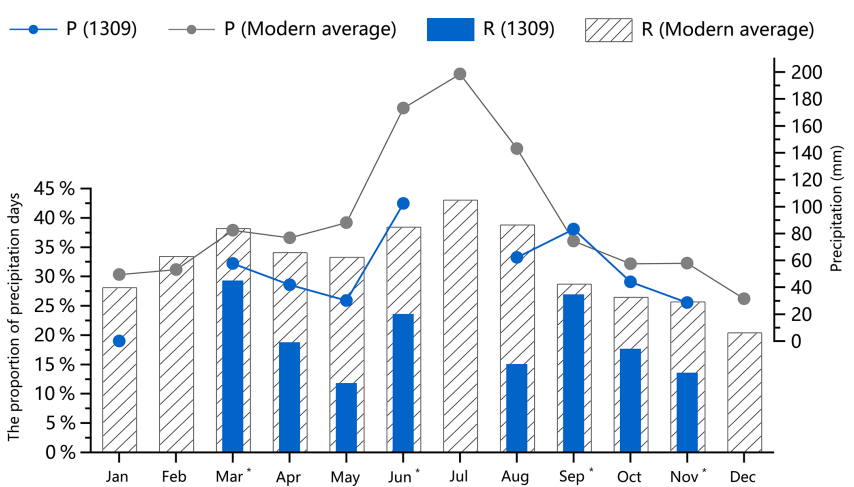

Figure 2. Precipitation and the proportion of precipitation days in Zhenjiang for each month of 1309 and their comparison with the modern averages. Notes: * indicates a month when Guo stayed entirely in Zhenjiang. The precipitation for February, July and December 1309 was not reconstructed due to insufficient data.

Of the modern meteorological stations, the Gaoyou station, which is the station closest to Zhenjiang, was chosen for analysis. The instrument-measured data obtained at the Gaoyou station for the period 1955-2018 demonstrate a significant positive correlation between $P$ and $R$ in each month, with a confidence level of $99.9 \%$. The correlation coefficients range from 0.55 to 0.9 . Table 3 summarizes the linear regression equations established between $P$ and $R$ for each month. When the independent variable $(R)$ is zero, the dependent variable $(P)$ should also be zero. Therefore, the linear regression model with no intercept is selected. Figure 2 shows the reconstructed results for monthly precipitation. 
Table 3. Linear regression equations between $P$ and $R$ for each month.

\begin{tabular}{lllllc}
\hline $\begin{array}{l}\text { Dependent } \\
\text { variable }\end{array}$ & $\begin{array}{l}\text { Independent } \\
\text { variable }\end{array}$ & Regression equation & $R^{2}$ & $F$ & $P$ \\
\hline$P_{1}$ & $R_{1}$ & $P_{1}=155.88 R_{1}$ & 0.819 & 285.2 & $<0.001$ \\
$P_{3}$ & $R_{3}$ & $P_{3}=198.54 R_{3}$ & 0.844 & 341.4 & $<0.001$ \\
$P_{4}$ & $R_{4}$ & $P_{4}=226.30 R_{4}$ & 0.867 & 412.3 & $<0.001$ \\
$P_{5}$ & $R_{5}$ & $P_{5}=261.90 R_{5}$ & 0.825 & 296.8 & $<0.001$ \\
$P_{6}$ & $R_{6}$ & $P_{6}=438.31 R_{6}$ & 0.842 & 334.8 & $<0.001$ \\
$P_{8}$ & $R_{8}$ & $P_{8}=419.42 R_{8}$ & 0.823 & 287.4 & $<0.001$ \\
$P_{9}$ & $R_{9}$ & $P_{9}=311.93 R_{9}$ & 0.771 & 208.7 & $<0.001$ \\
$P_{10}$ & $R_{10}$ & $P_{10}=252.92 R_{10}$ & 0.789 & 232.0 & $<0.001$ \\
$P_{11}$ & $R_{11}$ & $P_{11}=214.08 R_{11}$ & 0.822 & 290.3 & $<0.001$ \\
\hline
\end{tabular}

Notes: $P_{i}$ is the precipitation of month $i$ (unit: $\mathrm{mm}$ ); $R_{i}$ is the proportion of precipitation days of month $i$; $R^{2}, F$ and $P$ are the goodness of fit, the ratio of the regression mean square to the residual mean square and the significance level of the regression equation, respectively.

Here, the precipitation characteristics in the summer of 1309 are described briefly. In June 1309, there were 7 precipitation days in Zhenjiang, which is $4.5 \mathrm{~d}$ less than the modern average (1981-2010). The reconstructed precipitation in Zhenjiang for June 1309 is $102.3 \mathrm{~mm}$, which is $40 \%$ lower than the modern average (1981-2010). In July 1309, Guo primarily stayed in Xinghua. The integrity rate of daily weather descriptions for this month is low. Nevertheless, terms such as "extremely hot" and "unbearably hot" can be found on multiple occasions in the diary for this month. This suggests that the temperatures were relatively high throughout this month. In addition, only 2 precipitation days were recorded in the diary. On days without direct weather descriptions, Guo often did outdoor activities, such as excursions, boating and resting in the shade (e.g. "Mr. Zhan and I rowed a boat into the lake to enjoy the cool but were frustrated by the mosquitos" on 25 July). Therefore, it can be deduced that most of the days without weather descriptions were not precipitation days. Clearly, there were high temperatures and a low precipitation in Xinghua in July. In August 1309, Guo primarily stayed in Zhenjiang. Few days with precipitation records can be found in the diary for this month. The first precipitation record - "It rained so I felt happy" - is found in the entry for 25 August. This is likely because there had been no rain in the nearly $20 \mathrm{~d}$ before that. In summary, there was a relatively low precipitation in central and southern Jiangsu in the summer of 1309.

It is necessary to note that the precipitation events recorded in Guo's diary were those that he observed. Some precipitation events might have been too slight for humans to notice. Gimmi et al. (2007) believed that the lowest daily precipitation that humans can perceive is $0.3 \mathrm{~mm}$. And precipitation events that occurred in the night may also be ignored by humans. Therefore, the number of precipitation days extracted from the diary may be less than the actual number. In addition, the integrity rate of daily weather descriptions is quite low in some months, which may increase the uncertainty in the conclusion.

\subsubsection{Reconstruction of cold wave processes in winter based on daily weather descriptions}

There are a number of records, often vivid and detailed, relating to cold-weather phenomena, such as low temperatures, rain, snow and freezes, in Yunshan Diary for the period December 1308-February 1309. These records are highly valuable for understanding the climatic characteristics of the winter of 1308-1309. In this winter, Guo stayed in the TLB. Specifically, he stayed in Huzhou from 1 to 30 December and in Zhenjiang and Changzhou from 31 December to 28 February. Zhenjiang and Changzhou are geographically close and have similar wintertime climatic characteristics. Thus, they are viewed as the same region for analysis in the following study. Table 4 summarizes the daily weather conditions derived from Yunshan Diary in the winter of 1308-1309.

A cold wave is a weather event leading to a dramatic decrease in temperature, which is caused by the large-scale invasion of cold air from high latitudes to middle and low latitudes. According to the modern national standard in China, Cold Wave Levels (GB/T21987-2017), a cold wave refers to a cold-air event that results in a decrease in the minimum temperature in a location by $\geq 8^{\circ} \mathrm{C}$ within $24 \mathrm{~h}, \geq 10^{\circ} \mathrm{C}$ within $48 \mathrm{~h}$ or $\geq 12^{\circ} \mathrm{C}$ within $72 \mathrm{~h}$ and causes the minimum temperature in the location to be $\leq 4{ }^{\circ} \mathrm{C}$. The main weather characteristics of the invasion of a cold wave into Jiangsu include temperature decreases, strong winds, rain and snow. The invasion of a cold wave also results in a probability of precipitation of $92 \%$ (The editorial board of "The climate of Jiangsu Province" from Jiangsu Meteorological Bureau, 1992). Cold waves in late fall or early spring often cause frosts, while cold waves in the dead of winter may lead to freezing rain and the freezing of rivers, lakes and ports (P. Zhang et al., 2011). There will be a rise in temperature after a cold wave. 
Table 4. Daily weather conditions in the period December 1308-February 1309.

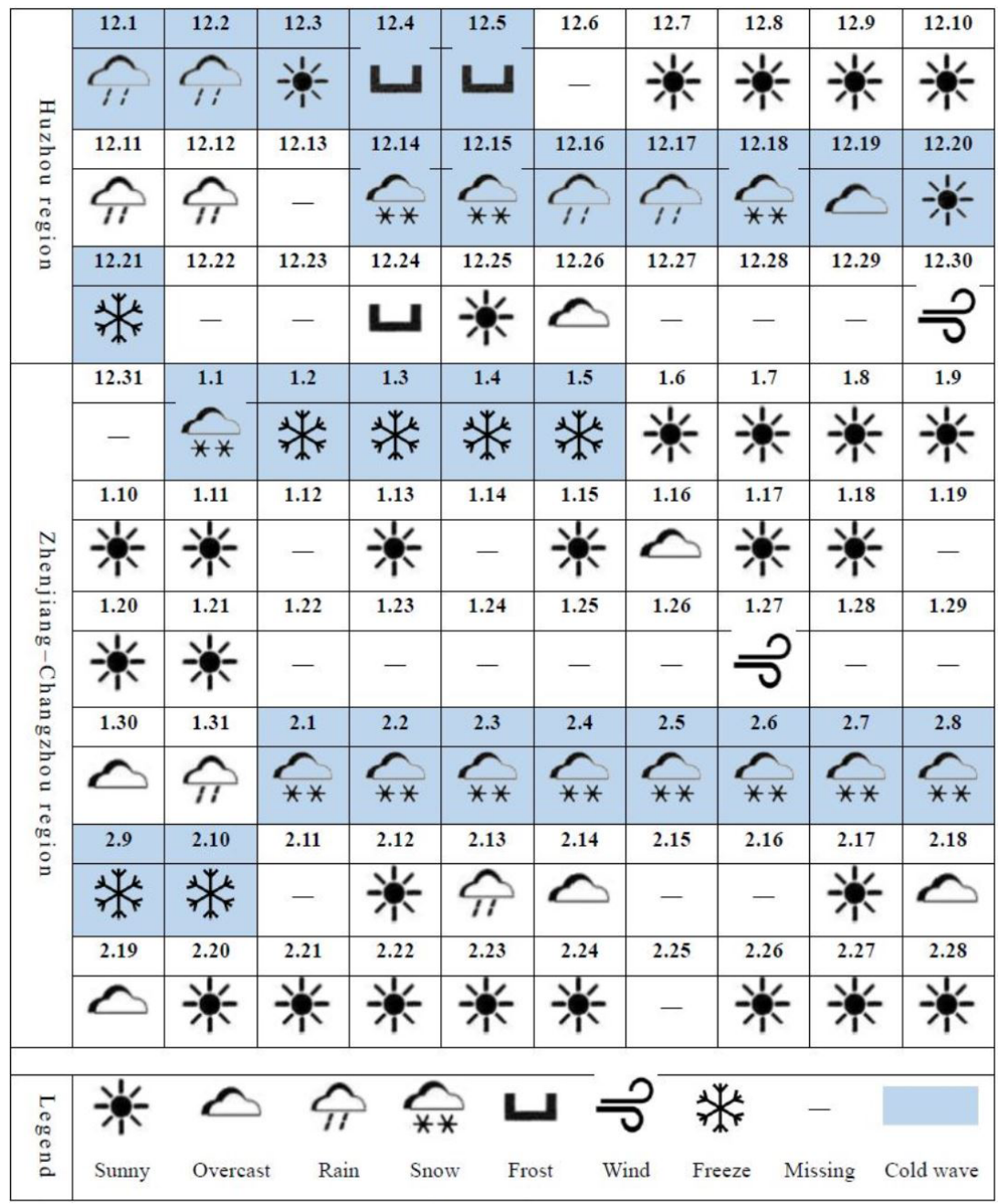

Notes: "freeze" means the freezing of water. In fact, frost and freeze are natural phenomena affected by weather, which are closely related to temperature. Therefore, they are also shown in this table.

It is impossible to deduce the extent of decrease in temperature based on the textual records in Yunshan Diary. Nevertheless, multiple records for weather phenomena (e.g. rain, snow, frosts, freezes and strong winds) closely related to cold waves can be found in the diary. Thus, periods in which these representative weather phenomena continuously occurred were extracted from the diary. On this basis, together with Guo's perceptions of temperature changes, it is deduced that at least four notable cold waves occurred in the TLB in the winter of 1308-1309 (highlighted in blue in Table 4). The third and fourth cold waves were extremely strong. In addition, there was a notable increase in temperature between two contiguous cold wave events, predominantly reflected by consecutive sunny days and subjective feelings such as "warm".

The third cold wave occurred between 1 and 5 January 1309. During this time, Guo was travelling on a boat back to Zhenjiang from Wuxi via the Jiangnan Canal, a section of the Beijing-Hangzhou Grand Canal. On 1 January, "A northeast wind broke out, and it was extremely cold"; and it began to snow at night. On 2 January, the weather remained "bitterly cold". In addition, the oar began to ice over, affecting the sailing. On 3 January, "Ice had closed in from all directions", and the canal was completely frozen. This rendered it impossible to sail the boat. The boatmen broke the ice and moved it onto the canal bank. Eventually, "piles of ice, two or three chi tall, were accumulated on the canal bank". Evidently, there was a considerably thick ice layer in the canal. On 4 January, the weather cleared up, but the temperature remained very low. "There was thick ice in the canal, and we could not move forward". On 5 January, it remained impossible to sail the boat. Guo had to abandon the boat and ride a horse home. Manifestly, the temperature was extremely low during this cold wave, and the Jiangnan Canal was frozen for at least $3 \mathrm{~d}$. 
The fourth cold wave occurred between 1 and 10 February 1309. There were 8 consecutive days of snowfall from 1 to 8 February. The snowfall was so heavy that Guo could not leave the house. In addition, there was a notable phenomenon of snow cover. There is a snowfall, snow cover or icing record for every day between 3 February, when "Snow-covered trees connected with one another", and 12 February, when "The snow melted". Thus, it can be deduced that snow cover lasted for approximately $10 \mathrm{~d}$. The snow cover was so deep that "No roads could be seen in all directions".

\section{Discussion}

\subsection{Climate change indicated in Yunshan Diary}

The following climatic characteristics can be derived from the above analysis. The climate in eastern China was colder in the early 14 th century than in the mid-13th century. In the summer of 1309 , there was relatively low precipitation in southern Jiangsu. In the winter of 1308-1309, it was abnormally cold in the TLB. On this basis, a combination of the records in the diary and other historical data or modern instrumental-measured data can help deduce the actual climate conditions at that time. A combination of multiple cases can help improve climate reconstruction for a certain time period or a certain region.

\subsubsection{Drought conditions in the summer of 1309}

As mentioned previously, there was a relatively low level of precipitation in central and southern Jiangsu Province in the summer of 1309. The precipitation (reconstructed value) in Zhenjiang in June was approximately $102.3 \mathrm{~mm}$, which is $40 \%$ lower than the modern average (1981-2010). In July, there were high temperatures and low precipitation in Xinghua. In August, the precipitation (reconstructed value) in Zhenjiang was approximately $62.1 \mathrm{~mm}$, which is $56 \%$ lower than the modern average (1981-2010).

Another piece of evidence showing that this summer was dry was the locust plague in central and southern Jiangsu Province. Dry environments provide suitable soil and climatic conditions for the growth, development and reproduction of locusts. Thus, droughts and locust plagues often occur concomitantly in China. There are two records relating to "locusts" in Yunshan Diary in early August 1309. These records involve the government's calls for people and boats to catch locusts.

The locust plagues in 1309 can also be confirmed by other historical records. According to the History of Yuan, locust plagues occurred in Nantong, Taizhou, Yangzhou, Nanjing and Gaoyou in Jiangsu Province in 1309. Other provinces, such as Shandong, Hebei, Henan, Anhui and Beijing, also suffered from locust plagues. There is a record that reads, "It was a dry year with scarce food" for Beijing (He, 2009; Zhang, 2004). The cross-validation of these records sug- gests that the summer of 1309 was relatively dry, and locust plagues occurred in many areas in North China and the middle and lower reaches of the Yangtze River.

\subsubsection{The severe cold winter of 1308-1309}

Due to a lack of instrument-measured data in the historical period, it is impossible to accurately reconstruct the temperature. Nonetheless, it is possible to derive some indices directly related to temperature from historical records, such as the number of snowfall days (Xiao et al., 2006; Zhang and Liang, 2017), the number of snow-cover days (Xiao et al., 2006; Yan et al., 2014) and the snow-cover depth (Zhang and Liang, 2014, 2017). Some space-related indices, such as the southern boundary of snowfall (Wang et al., 2004) and the southern boundary of river freezing (Wang et al., 2004; Zhang and Liang, 2017), are also available when there were abundant records in different locations. Through these indices, historical cold winters can be compared with the average conditions and extremely cold years in modern times (Table 5). On this basis, the extent of coldness and the climatic characteristics in the historical period can be deduced.

In January 1309, the Jiangnan Canal was frozen for at least $3 \mathrm{~d}$. There was a relatively thick ice layer in the canal, rendering it impossible to sail boats. Based on the hydrological characteristics of rivers in the Jiangnan region, Zhang et al. (1977) deduced that the critical temperature for the river to completely freeze in this region is approximately -13 to $-15^{\circ} \mathrm{C}$. In modern years when the Jiangnan Canal was frozen (1955 and 1969), the extreme daily minimum temperatures were indeed lower than $-13^{\circ} \mathrm{C}$ at the nearby meteorological stations. This demonstrates that the above conclusion is reliable in general. On this basis, it is inferred that the minimum temperature in Zhenjiang might have reached below $-13^{\circ} \mathrm{C}$ when the river was frozen between 3 and 5 January 1309. According to the modern instrument-measured data, there were only 3 years with an extreme minimum temperature below $-13^{\circ} \mathrm{C}$ in the Zhenjiang-Changzhou region from 1954 to 2019 . The lowest daily minimum temperature $\left(-17^{\circ} \mathrm{C}\right)$ in January in this region occurred in 1955 . In early January 1955 , the minimum temperatures in the middle and lower reaches of the Yangtze River reached -10 to $-15^{\circ} \mathrm{C}$. Except for the main stream of the Yangtze River, all the rivers and lakes were frozen, mostly to depths of $16-35 \mathrm{~cm}$. Boats were frozen in the Han River and the Dongting Lake (Ding, 2008; Feng et al., 1985). Evidently, the climatic conditions in January 1309 were quite similar to those in January 1955 - an intense cold wave occurred in early January, causing the lakes and rivers in the lower reaches of the Yangtze River to freeze. However, due to a lack of data, it is impossible to determine the weather conditions in January 1309 in regions other than the Zhenjiang-Changzhou region.

In February 1309, there were 8 consecutive days of snowfall and 10 consecutive days of snow cover in the ZhenjiangChangzhou region. The roads were buried in snow, severely 
Table 5. Climatic indices of the Zhenjiang-Changzhou region in January and February 1309 and their comparison with those obtained from modern instrument-measured records.

\begin{tabular}{lrrrrr} 
& 1309 & Average for & \multicolumn{3}{c}{ Modern extreme cold-winter } \\
& & $1953-2010$ & \multicolumn{3}{c}{ years } \\
\cline { 3 - 6 } & & & 1955 & 1969 & 1977 \\
\hline$N_{\mathrm{S}}$ in January (days) & 1 & 3.8 & 5 & 5.5 & 14.5 \\
$R_{\mathrm{S}}$ in January & $33.33 \%$ & $38.10 \%$ & $71.42 \%$ & $42.31 \%$ & $93.55 \%$ \\
$N_{\mathrm{S}}$ in February (days) & 8 & 3.1 & 5 & 9.5 & 2.5 \\
$R_{\mathrm{S}}$ in February & $88.89 \%$ & $28.77 \%$ & $33.33 \%$ & $59.38 \%$ & $38.46 \%$ \\
Minimum temperature in January $\left({ }^{\circ} \mathrm{C}\right)$ & $<-13$ & -6.7 & -17 & -8.4 & -15.3 \\
Minimum temperature in February $\left({ }^{\circ} \mathrm{C}\right)$ & - & -5.3 & -4.9 & -14.2 & -12.2 \\
Average temperature in January $\left({ }^{\circ} \mathrm{C}\right)$ & - & 2.8 & -0.7 & 2.1 & -0.7 \\
Average temperature in February $\left({ }^{\circ} \mathrm{C}\right)$ & - & 4.6 & 6.2 & 0.7 & 2.4 \\
\hline
\end{tabular}

Note: $N_{\mathrm{S}}$ : the number of snowfall days; $N_{\mathrm{p}}$ : number of precipitation days (including rainfall days and snowfall days). $R_{\mathrm{S}}:$ rate of snowfall $=\frac{N_{\mathrm{S}}}{N_{\mathrm{p}}}$ (Gong et al., 1983b).

affecting people's commutes. The canal was also frozen. In modern times, on average, there are approximately 3.1 snowfall days and 2.8 snow-cover days in this region in February, far fewer than the numbers in February 1309. Clearly, the snowfall and snow-cover conditions in February 1309 were quite rare. According to the instrument-measured records from 1954 to 2019, the lowest daily minimum temperature $\left(-14.2^{\circ} \mathrm{C}\right)$ in the Zhenjiang-Changzhou region in February occurred in 1969. In 1969, as a result of the continuous strong cold waves from late January to early February, there were $6 \mathrm{~d}$ of snowfall at Liyang station in Changzhou. The BeijingHangzhou Grand Canal was frozen from late January to early March (P. Zhang et al., 2011). The Yellow River and the Bohai Sea were also frozen (Ding, 2008).

Compared to the winter of 1308-1309, there have been a few similarly cold or even colder winters in modern times. However, it is worth noting that the extremely cold phenomena (e.g. low temperatures, snow and freezing) in modern winters have mostly been caused by one or several continuous strong cold waves. For example, in 1955, temperatures were abnormally low in January but became relatively normal in February. In 1977, the minimum temperatures in January and February were both seemingly very low. However, this is because the strongest cold wave that year occurred between late January and early February. By contrast, in 1309, there were two extremely strong cold waves, one in January and another in February. As a result, the Jiangnan Canal was completely frozen in January, and the number of snowfall days and snow-cover days were both abnormally high in February. During the interval of more than $20 \mathrm{~d}$ between the two cold waves, there was a notable rise in temperature. It is quite unusual.

The winter of 1308-1309 was abnormally cold. It would have also been rare even it were to occur amid the modern climatic background. Zheng et al. (2005) analysed the winter temperature anomaly sequence in eastern China from 1951 to
1995. The results show that the average temperature anomaly of every 10 years is positively correlated with the temperature anomalies of abnormally cold years among the 10 years. The correlation coefficient is 0.965 , and the significance level is 0.001 . Thus, it can be inferred that the first decade of the 1300 s was relatively cold on an interdecadal scale.

\subsubsection{Transition from the MWP to the LIA in the early 14 th century}

The Medieval Warm Period (MWP) approximately corresponds to the 9th-13th century in China, i.e. the period from the Five Dynasties period to the early Yuan dynasty (Ge et al., 2013; Man, 1999). In this period, the 13th century was the warmest, comparable to the 20th century (Ge et al., 2002b). The Little Ice Age (LIA) refers to the cold period following the MWP. Most scholars agree that the LIA began at least after the 15th century in China, approximately corresponding to the Ming and Qing dynasties. Hence, the LIA is also referred to as the "the Little Ice Age of the Ming and Qing dynasties" (Wang, 1995; Wang et al., 2006; Zhang et al., 2013b).

Yunshan Diary was written in the early 14th century when the climate was turning from the MWP to the LIA. According to the winter-half-year temperature sequence for eastern China for the past 2 millennia, the most rapid decrease in temperature (at a rate of $1.4^{\circ} \mathrm{C}$ per 90 years) occurred between the mid- and late-13th century and the early 14 th century. The 30 years between 1290 and 1320 were the key period when the temperature anomaly turned from positive to negative (Ge et al., 2002a, b). The northern planting boundary of citrus recorded in Yunshan Diary was notably further south than that in the mid-13th century. This demonstrates that on a multidecadal scale, the climate in the early 14th century was no longer as warm as that at the height of the MWP. In northern China, cold disasters, such as snowstorms, have been frequent since the 14th century (Hao et 
al., 2009). These pieces of evidence reflect the continuous climate-cooling process when the MWP was turning to the LIA.

\subsection{Advantages and disadvantages of climate records in ancient diaries}

Compared to other types of documentary data used in climate reconstruction, the records in private diaries have the following advantages. (1) Diaries are reliable and veracious. This is because the content of a diary is the author's own experience, written at the time when things occurred. In addition, diary authors did not need to take into consideration any other factors (e.g. political factors) when writing their diaries and were therefore able to objectively record natural phenomena. (2) The records in diaries have little uncertainty in time and location. In Yunshan Diary, every record is accompanied by a clear date. The location can be deduced from the author's life experience and travel routes, which are recorded in the diary. (3) The records have a high temporal resolution and can supply daily or even subdaily weather information. For example, one record in Yunshan Diary reads, "It was sunny and warm in the daytime and rained heavily at night." (4) Diaries can reflect human interactions with climate, including the impact of climate on humans and the responses of humans to climate. For example, some records in Yunshan Diary show that people changed clothes when it was getting cooler. (5) Diaries are seasonally continuous and complete. By contrast, history books, local gazettes and agricultural books are often focused on climatic characteristics during farming seasons as well as meteorological events that affected agriculture and social stability (Adamson, 2015; Gong et al., 1983a; Linderholm and Molin, 2005; Pfister et al., 1999; Pillatt, 2012; Zhang et al., 2007a).

Private diaries also have some disadvantages. (1) Diaries are relatively subjective. Owing to personal experience and character, authors differ in their attention and sensitivity to weather. (2) Diaries often have problems of missing records and changes in the record location. These problems are notable in Yunshan Diary. Due to location inconsistencies, it is impossible to reconstruct continuous climate series. Only the time periods with consistent locations are selected for analysis. (3) Diaries cover short periods of time. Limited by the life span and living conditions of the author, diary records cover several months at the shortest and several decades at the longest (Adamson, 2015; Huang et al., 2013; Pfister et al., 1999, 2008).

In summary, in historical climate research, private diaries are suitable for reconstructing short-term, high-resolution climate series, extreme climatic events and specific meteorological processes. They are also useful in studying the impact of climate on human lives and the responses of humans to climate. In addition, diaries can serve as supplemental data for long-term climate research.

\section{Conclusions}

Private diaries are a main type of documentary evidence for studying historical climate change. They have a number of advantages, including high veracity and reliability, accurate time and location information, high temporal resolution, seasonal integrity, and rich content. On the other hand, private diaries have the limitations of strong subjectivity, short recording periods, missing records, and location inconsistencies. Therefore, when extracting records from diaries, it is necessary to carefully examine and assess the information. Each record should contain three clear elements, namely, time, location and climatic/weather event. In climate reconstruction, it is critical to select suitable quantification indices and research methods, eliminate as much interference from the author's subjectivity as possible, and highlight objective natural phenomena and their climatic significance.

Climatic information in diaries mainly includes species distribution records, phenological records, daily weather descriptions and personal experiences of meteorological conditions. Species distribution records can be used as evidence for long-term climate change. Phenological records reflect interannual climatic characteristics. Daily weather descriptions are the unique advantages of private diaries and can be used to reconstruct short-term meteorological processes or high-resolution climate series. Personal experiences of meteorological conditions are relatively subjective and can be used to supplement weather descriptions. The comparison of diary records with modern instrument-measured data or other documentary data can help clarify their climatic significance.

This article presents a case study of an ancient Chinese diary of the Yuan dynasty - Yunshan Diary. The records relating to weather and climate in this diary were extracted, and their climate significance was analysed. The following conclusions are drawn. (1) In the summer of 1309, the precipitation was low in central and southern Jiangsu Province. This region also suffered from a locust plague. (2) The winter of 1308-1309 was abnormally cold. In this winter, there were at least four cold waves in the TLB. In January 1309 , the Jiangnan Canal was completely frozen, and the minimum temperature might have reached $-13^{\circ} \mathrm{C}$. In February 1309 , there were 8 consecutive days of snowfall and 10 consecutive days of snow cover in the Zhenjiang-Changzhou region, both of which are far greater than modern averages. (3) In the early 14th century at the latest, the climate in eastern China had begun to turn cold. This reflects the transition from the MWP to the LIA.

Data availability. All the data used to perform the analysis in this study are described and properly referenced in the paper. Yunshan Diary is available in A Series of Diaries of the Jin and Yuan Dynasties published by Shanghai Bookstore Publishing House ( $\mathrm{Gu}$ and $\mathrm{Li}$, 2013). Most of the modern meteorological data are available from the China Meteorological Data Service Center (2020a, b, c). 
Author contributions. SC collected data, calculated statistics and performed most of the analysis with guidance of YS. YS designed the research method, supervised the study and assisted with interpreting the results. XF had the idea for the study, defined the outline of this manuscript and made some revisions. SC and JH made the figures and drafted the manuscript. All authors participated in the analysis, provided critical feedback and helped to improve the article.

Competing interests. The author declares that there is no conflict of interest.

Special issue statement. This article is part of the special issue "International methods and comparisons in climate reconstruction and impacts from archives of societies". It is not associated with a conference.

Acknowledgements. We would like to thank all colleagues in our research group in Beijing Normal University, who provided valuable discussions and suggestions. We would like to thank the anonymous reviewers and editors for their valuable comments.

Financial support. This research has been supported by the National Natural Science Foundation of China (grant no. 41771572) and the National Key Research and Development Program of China (grant no. 2018YFA0605602).

Review statement. This paper was edited by Sam White and reviewed by two anonymous referees.

\section{References}

Adamson, G. C. D.: Private diaries as information sources in climate research, WIREs Clim. Change, 6, 599-611, https://doi.org/10.1002/wcc.365, 2015.

Adamson, G. C. D. and Nash, D. J.: Long-term variability in the date of monsoon onset over western India, Clim. Dynam., 40, 2589-2603, https://doi.org/10.1007/s00382-012-1494-x, 2013.

Adamson, G. C. D. and Nash, D. J.: Documentary reconstruction of monsoon rainfall variability over western India, 1781-1860, Clim. Dynam., 42, 749-769, 2014.

Chen, D.: The semantic analysis and cultural interpretation on morpheme "Frost" and the terms combined with it - Explaining the "Frost" in Compete Tang Poems, Master thesis, College of Chinese Language and Literature, Fujian Normal University, China, 163 pp., 2018 (in Chinese with English abstract).

Chen, Z.: Talking about the diaries of all generations in Chinese history, Shanghai pictorial press, Shanghai, China, 2004.

China Meteorological Data Service Center: Standard Monthly Surface Climate Dataset for China (1981-2010), available at: http://data.cma.cn/data/cdcdetail/dataCode/SURF_CLI_ CHN_MUL_MMON_19812010.html, last access: 20 February 2020a.
China Meteorological Data Service Center: Monthly Surface Climate Dataset for China, available at: http://data.cma.cn/data/ cdcdetail/dataCode/SURF_CLI_CHN_MUL_MON.html, last access: 5 March 2020b.

China Meteorological Data Service Center: Daily Surface Climate Dataset for China (V3.0), available at: http://data.cma.cn/data/ cdcdetail/dataCode/SURF_CLI_CHN_MUL_DAY_V3.0.html, last access: 14 March 2020c.

Chu, K.: A preliminary study on the climatic fluctuations during the last 5,000 years in China, Sci. China Ser. A, 3, 226-256, 1973.

Ding, Y.: China meteorological disasters ceremony: Synthetic Study, China Meteorological Press, Beijing, China, 2008 (in Chinese).

Fang, X., Xiao, L., Ge Q., and Zheng, J.: Changes of plants phenophases and temperature in spring during 1888-1916 around Changsha and Hengyang in Hunan province, Quaternary Sciences, 25, 74-79, 2005 (in Chinese with English abstract).

Fei, J., Zhou, J., Zhang, Q., and Chen, H.: A Preliminary Investigation on the Dusty Days in Beijing over 1860-1898 A.D., Journal of Glaciology and Geocryology, 26, 535-539, 2004 (in Chinese with English abstract).

Fei, J., Zhou, J., Zhang, Q., and Chen, H.: Dust weather records in Beijing during 1860-1898 AD based on the Diary of Tonghe Weng, Atmos. Environ., 39, 3943-3946, 2005.

Fei, J., Hu, H., Zhang, Z., Zhou, Z., and Zhou, J.: Research on dust weather in Beijing during 1860-1898 - inferred from the Diary of Tonghe Weng, Journal of Catastrophology, 24, 116-120+136, 2009 (in Chinese with English abstract).

Feng, P., Li, C., and Li, X.: Analysis of major meteorological disasters in China: 1951-1980, China Meteorological Press, Beijing, China, 1985 (in Chinese).

Ge, Q., Zheng, J., Fang, X., Man, Z., Zhang, X., Zhang, P., and Wang, W.: Temperature changes of winter-half-year in eastern China during the past 2000 years, Quaternary Sciences, 22, 166173, 2002a (in Chinese with English abstract).

Ge, Q., Zheng, J., Man, Z., Fang, X., and Zhang, P.: Reconstruction and analysis on the series of winter-half-year temperature changes over the past 2000 years in eastern China, Earth Science Frontiers, 9, 169-181, 2002b (in Chinese with English abstract).

Ge, Q., Liu, J., Fang, X., Yang, B., Hao, Z., Shao, X., and Zheng, J.: General characteristics of temperature change and centennial warm periods during the past 2000 years, Acta Geographica Sinica, 68, 579-592, 2013 (in Chinese with English abstract).

Ge, Q., Hao, Z., Zheng, J., and Liu, Y.: China: 2000 Years of Climate Reconstruction from Historical Documents, in: The Palgrave Handbook of Climate History, edited by: White, S., Pfister, C., and Mauelshagen, F., Palgrave Macmillan, London, UK, 189-202, https://doi.org/10.1057/978-1-137-43020-5_17, 2018.

Gergis, J., Karoly, D. J., and Allan, R. J.: A climate reconstruction of Sydney Cove, New South Wales, using weather journal and documentary data, 1788-1791, Aust. Meteorol. Ocean., 58, 8398, https://doi.org/10.22499/2.5802.001, 2012.

Gimmi, U., Luterbacher, J., Pfister, C., and Wanner, H.: A method to reconstruct long precipitation series using systematic descriptive observations in weather diaries: the example of the precipitation series for Bern, Switzerland (1760-2003), Theor. Appl. Climatol., 87, 185-199, 2007.

Gong, G. and Zhang, P.: Textural research and analysis on the freezing injury of citrus in Chinese history, in: Study on the freeze in- 
jury of Chinese citrus, edited by: Zhang, W. and Jiang, A., China Agriculture Press, Beijing, China, 11-16, 1983 (in Chinese).

Gong, G., Zhang, P., Wu, X., and Zhang, J.: Research Methods of Climate Change in Historical Periods, Science Press, Beijing, China, 1983a (in Chinese).

Gong, G., Zhang, P., and Zhang, J.: A study on the climate of the 18 th century of the lower Changjiang valley in China, Geogr. Res., 2, 20-33, 1983b (in Chinese with English abstract).

Grab, S. W. and Nash, D. J.: Documentary evidence of climate variability during cold seasons in Lesotho, Southern Africa, 1833-1900, Clim. Dynam., 34, 473-499, https://doi.org/10.1007/s00382-009-0598-4, 2009.

Grossman, M. and Zaiki, M.: Reconstructing typhoons in Japan in the 1880s from documentary records, Weather, 64, 315-322, https://doi.org/10.1002/wea.401, 2009.

$\mathrm{Gu}, \mathrm{H}$. and $\mathrm{Li}, \mathrm{W}$. (Eds): A series of diaries in the Jin and Yuan dynasty, Shanghai bookstore publishing house, Shanghai, China, 2013 (in Chinese).

Hao, Z., Ge, Q., and Zheng, J.: Temperature variations during the Song and Yuan dynasties (960-1368 A.D.) in the eastern part of North West China, Quaternary Sciences, 29, 871-879, 2009 (in Chinese with English abstract).

He, F.: General History of Disasters in China: the Yuan Dynasty, Zhengzhou University Press, Zhengzhou, China, 2009 (in Chinese).

Hirano, J. and Mikami, T.: Reconstruction of winter climate variations during the 19th century in Japan, Int. J. Climatol., 28, 14231434, https://doi.org/10.1002/joc.1632, 2008.

Huang, X.: Planning and Comprehensive Treatment of the Taihu Lake Basin, China Water \& Power Press, Beijing, China, 2000 (in Chinese).

Huang, Y., Li, B., and Li, Z.: Review of climate reconstruction based on ancient diary, Progress in Geography, 32, 1545-1554, 2013 (in Chinese with English abstract).

Lee, D. S. and Mackenzie, A. R.: Trans-hemispheric effects of large volcanic eruptions as recorded by an early 19th century diary, Int. J. Climatol., 30, 2217-2228, https://doi.org/10.1002/joc.2034, 2010.

Linderholm, H. W. and Molin, T.: Early nineteenth century drought in east central Sweden inferred from dendrochronological and historical archives, Clim. Res., 29, 63-72, https://doi.org/10.3354/cr029063, 2005.

Liu, B. and Man, Z.: A study on climatic of cold and warm from 1609-1616 A.D. in Wei Shuixuan Diary in the lower reaches of Yangtze River, Journal of Chinese Historical Geography, 27, 1622, 2012 (in Chinese with English abstract).

Liu, Y., Fang, X., Tao, Z., and Dai, J.: Basic features of phenological records in poetry and their usage for reconstructing past climate change, Progress in Geography, 36, 483-490, 2017 (in Chinese with English abstract).

Man, Z.: Climate in Tang Dynasty of China: discussion for its evidence, Quaternary Sciences, 20-30, 1998 (in Chinese with English abstract).

Man, Z.: Relationship between geographic Northern bounds of orange cultivation in Chinese history and the climatic changes, Fudan Journal(Social Sciences Edition), 72-77+142, 1999 (in Chinese with English abstract).

Man, Z.: Proxy data and its problem in the historical literature, in: Historical geography facing to the new century - Proceedings of 2000 international symposium on Chinese historical geography, Kunming, China, 2-6 August 2000, 56-75, 2000 (in Chinese with English Abstract).

Man, Z.: Research on climate change in China's historical period, Shandong Education Press, Jinan, China, 2009.

Man, Z. and Yang, Y.: The Medieval Warming impacts on the natural environment in eastern China as inferred from historical documents, Quaternary Sciences, 34, 1197-1203, 2014 (in Chinese with English abstract).

Man, Z., Li, Z., and Yang, Y.: Characteristics of Meiyu during 1867-1872 in Wuhan and Changsha areas recorded in Wang Wenshao Diary, Journal of Palaeogeography, 9, 431-438, 2007 (in Chinese with English abstract).

Mikami, T.: Climatic variations in Japan reconstructed from historical documents, Weather, 63, 190-193, https://doi.org/10.1002/wea.281, 2008.

Nash, D. J. and Grab, S. W.: "A sky of brass and burning winds": documentary evidence of rainfall variability in the Kingdom of Lesotho, Southern Africa, 1824-1900, Climatic Change, 101, 617-653, https://doi.org/10.1007/s10584-009-9707-y, 2010.

Nordli, P. Ø.: Reconstruction of nineteenth century summer temperatures in Norway by proxy data from farmers' diaries, Climatic Change, 48, 201-218, https://doi.org/10.1007/978-94-017-33526_10, 2001.

PAGES: Science plan and implementation strategy, IGBP Secretariat, Stockholm, Sweden, IGBP Report No. 57, 35-52, 2009.

Perpetual calendar editing group: The Chinese Almanac for Two Thousand Years, China Meteorological Press, Beijing, China, 1994 (in Chinese).

Pfister, C., Brázdil, R., Glaser, R., Bokwa, A., Holawe, F., Limanowka, D., Kotyza, O., Munzar, J., Rácz, L., Strömmer, E., and Schwarz-Zanetti, G.: Daily Weather Observations in Sixteenth-Century Europe, Climatic Change, 43, 111-150, https://doi.org/10.1007/978-94-015-9259-8_4, 1999.

Pfister, C., Luterbacher, J., Wanner, H., Wheeler, D., Brázdil, R., Ge, Q., Hao, Z., Moberg, A., Grab, S., and Rosario del Prieto, M.: Documentary evidence as climate proxies, PAGES/CLIVAR Proxy Uncertainty Workshop, Trieste, Italy, June 2008.

Pillatt, T.: Experiencing Climate: Finding Weather in Eighteenth Century Cumbria, J. Archaeol. Method Th., 19, 564-581, https://doi.org/10.1007/s10816-012-9141-8, 2012.

Raicich, F.: Some features of Trieste climate from an eighteenth century diary (1732-1749), Climatic Change, 86, 211-226, 2008.

Tan, Q.: The Historical Atlas of China, Vol. VII: the Yuan Dynasty Period, the Ming Dynasty Period, SinoMaps Press, Beijing, China, 1982 (in Chinese).

The editorial board of "The climate of Jiangsu Province" from Jiangsu Meteorological Bureau: The climate of Jiangsu Province, China Meteorological Press, Beijing, China, 1992 (in Chinese).

The reference room of Beijing meteorological center: The surface climatological data for China, 1951-1980, Vol. 3: East China, China Meteorological Press, Beijing, China, 1984 (in Chinese).

Vliet, A. J. H. V. and Groot, R. S. D.: "Challenging times" in the context of the European phenology network, in: Challenging times: towards an operational system for monitoring, modeling, and forecasting of phenological changes and their socioeconomic impact, edited by: Vliet, A. J. H. V., Wageningen University, Wageningen, Netherlands, 10-17, 2003. 
Wan, M.: Selected Natural Calendars of China, Science Press, Beijing, China, 1986 (in Chinese).

Wan, M. and Liu, X.: Phenological observation methods in China, Science Press, Beijing, China, 1979 (in Chinese).

Wan, M. and Liu, X.: Chinese flora and fauna phenology atlas, China Meteorological Press, Beijing, China, 1986 (in Chinese).

Wang, J., Chen, F., Yang, B., and Chen, J.: New advances in research on the Little Ice Age climate change, Advances in Climate Change Research, 2, 21-27, 2006 (in Chinese with English abstract).

Wang, J. and Zuo, W.: Geographic Atlas of China, SinoMaps Press, Beijing, China, 2010 (in Chinese).

Wang, P., Fang, X., and He, L.: Historical records on cold events and their influence during 1328-1330 AD in China, Journal of Palaeogeography, 6, 480-484, 2004 (in Chinese with English abstract).

Wang, S.: Studies on climate of the Little Ice Age, Quaternary Sciences, 15, 202-212, 1995 (in Chinese with English abstract).

Wu, W., Lu, A., and Fei, Q.: Research on Climate Resources of Taihu Lake Basin, China Meteorological Press, Beijing, China, 1993 (in Chinese).

Xiao, L., Fang X., and Zhang, X.: Severe 1877-1878 winter in Changsha city of Hunan Province recorded in the book Xiangqilou Diary, Journal of Palaeogeography, 8, 277-284, 2006 (in Chinese with English abstract).

Xiao, L., Fang X., and Zhang, X.: Location of rainbelt of Meiyu during second half of 19 th century to early 20 th century, Scientia Geographica Sinica, 28, 385-389, 2008 (in Chinese with English abstract).

Xu, X., Yang, G., Tan, Y., Tang, X., Jiang, H., Sun, X., Zhuang, Q., and Li, H.: Impacts of land use changes on net ecosystem production in the Taihu Lake Basin of China from 1985 to 2010, J. Geophys. Res.-Biogeo., 122, 690-707, https://doi.org/10.1002/2016JG003444, 2017.

Yan, C., Fang, X., Ye, Y., and Zhang X.: Reconstruction of plum rain season and its rainfall of Shanghai in 1849 based on records of the flood in 1849, Journal of Palaeogeography, 13, 96-102, 2011 (in Chinese with English abstract).

Yan, J., Liu, H., Zheng, J., Hao, Z., Ge, Q., and Fu, H.: The extreme cold winter of 1620 in the middle and lower reaches of the Yangtze River, Progress in Geography, 33, 835-840, 2014 (in Chinese with English abstract).

Yang, Y., Cheng, S., and Man, Z.: High-resolved sand dust records of Beijing in the middle of 19th century: A preliminary study of Weng Xincun Diary, Journal of Palaeogeography, 15, 565-574, 2013 (in Chinese with English abstract).

Yu, W.: Guo Tianxi and his Yunshan Diary, The Documentat, 222232, 1989

Zhang, D.: A Compendium of Chinese Meteorological Records of the Last 3,000 years, Phoenix Publishing House, Nanjing, China, 2004 (in Chinese).

Zhang, D. and Liang, Y.: A study of the severest winter of $1892 / 1893$ over China as an extreme climatic event in history, Quaternary Sciences, 34, 1176-1185, 2014 (in Chinese with English abstract).

Zhang, D. and Liang, Y.: A study of the severest winter of $1670 / 1671$ over China as an extreme climatic event in history, Climate Change Research, 13, 25-30, 2017 (in Chinese with English abstract).
Zhang, F., Gong, G., and Zhang, P.: The south border of citrus freeze to death and river freeze up for the last 500 years, in: Proceedings of Climatic Change and Ultra-long Range Weather Forecasting, edited by: Institute of Meteorology, Central Meteorological Bureau, Science Press, Beijing, China, 33-35, 1977 (in Chinese).

Zhang, P.: Historical climate change in China, Shandong Science and Technology Press, Jinan, China, 1996 (in Chinese).

Zhang, P., Wei, Y., Cao, N., Peng, X., and Huang, L.: Weather characteristics and forecast indexes of cold waves in Jiangsu province, in: The 28th annual meeting of China Meteorological Society - S3, Weather forcast, disastrous weather research and forcast, Xiamen, China, 9-11 November, 1-11, 2011 (in Chinese with English abstract).

Zhang, X., Fang, X., Tian, Q., and Wang, L.: Sand dust weather of Beijing in the later half of 19th century recorded in the book Weng Tonghe Diary, Journal of Palaeogeography, 8, 117-124, 2006 (in Chinese with English abstract).

Zhang, X., Fang, X., and Qi, X.: Perception records on cold/warm in Weng Tonghe Diary and its significance to cold/warm variation, Journal of Palaeogeography, 9, 439-446, 2007a (in Chinese with English abstract).

Zhang, X., Fang, X., Zheng, J., and Xiao, L.: Adaptation to Climate Change in Date of Seasonal Dressing Change in Beijing during Late 19th Century, Resources Science, 29, 93-98, 2007b (in Chinese with English abstract).

Zhang, X., Fang, X., Zheng, J., and Hao, Z.: Reconstructed precipitation in Beijing during 1860-1897 based on the weather records from "Diary of Weng Tonghe", Climatic and Environmental Research, 16, 322-328, 2011 (in Chinese with English abstract).

Zhang, X., Ge, Q., Fang, X., Zheng, J., and Fei, J.: Precipitation variations in Beijing during 1860-1897 AD revealed by daily weather records from the Weng Tong-He Diary, Int. J. Climatol., 33, 569-576, 2013a.

Zhang, X., Shao, X., and Wang, T.: Regional climate characteristics in China during the Little Ice Age, Journal of Nanjing University of Information Science \& Technology (Natural Science Edition), 5, 317-325, 2013b (in Chinese with English abstract).

Zhang, X., Li, Y., Wang, Y., Cai, H., Zeng, H., and Wang, Z.: Influence of future climate change in suitable habitats of tea in different countries, Biodiversity Science, 27, 595-606, 2019 (in Chinese with Englis abstract).

Zheng, J., Man, Z., Fang, X., and Ge, Q.: Temperature variation in the eastern China during Wei Jin and South-North Dynasties (220-580 A.D.), Quaternary Sciences, 25, 129-140, 2005 (in Chinese with English abstract).

Zheng, J., Ge. Q., Hao, Z., Liu, H., Man, Z., Hou, Y., and Fang, $\mathrm{X}$. : Paleoclimatology proxy recorded in historical documents and method for reconstruction on climate change, Quaternary Sciences, 24, 1186-1196, 2014 (in Chinese with English Abstract).

Zheng, J., Liu, Y., Ge, Q., and Hao, Z.: Spring phenodate records derived from historical documents and reconstruction on temperature change in Central China during 1850-2008, Acta Geographica Sinica, 70, 696-704, 2015 (in Chinese with English abstract). 